\title{
Time for Dementia: an innovation in education
}

Wendy Grosvenor, Lecturer, Older Adult Care, School of Health Sciences, Faculty of Health and Medical Sciences, University of Surrey, Guildford; Molly Hebditch, Time for Dementia Research Worker, School of Health Sciences, Faculty of Health and Medical Sciences, University of Surrey, Guildford; Stephanie Daley, Clinical Research Fellow and Time For Dementia Lead, Centre for Dementia Studies, Sussex Partnership NHS Foundation Trust; Emma Vyvyan, Teaching Fellow, Integrated Care (Paramedic Practice), School of Health Sciences, Faculty of Health and Medical Sciences, University of Surrey, Guildford; Sube Banerjee, Professor of Dementia, Centre for Dementia Studies, Brighton and Sussex Medical School.

E-mail for correspondence: w.grosvenor@surrey.ac.uk

\section{Abstract}

This paper describes an innovative undergraduate educational initiative called the Time for Dementia programme. It was developed to improve the knowledge, attitudes and skills in dementia among healthcare students. Time for Dementia involves pairs of healthcare students (medical, paramedic, adult and mental health nursing, and allied health professionals) visiting a person with dementia and their carer in their homes over a period of 2 years. The aim of the programme is to enable students to learn with people with dementia and their carers-recognising that people with dementia have unique expertise derived from their experiences. Their personal narratives offer students a unique insight into the subjective experiences of dementia.

\section{Key words}

- Pre-registration $\bullet$ Paramedic $\bullet$ Education $\bullet$ Dementia $\bullet$ Carers

- Person-centred care

Accepted for publication 24 October 2017.

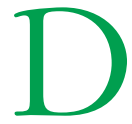
ementia is a global condition affecting 46 million people with an annual cost of $\$ 600$ billion. Case numbers will double, and costs will at least triple, in the next 20 years (Alzheimer's Disease International, 2010; Prince et al, 2013).

\section{Time for Dementia programma}

Time for Dementia (Banerjee et al, 2016) is an educational programme for undergraduate healthcare students including medical, adult and mental health nursing, and allied health professionals, as well as paramedic students. The programme involves students visiting a family affected by dementia in their homes over a 2-year period in order to enhance their skills and knowledge about the condition.
The programme was established to address limitations in the skills of healthcare personnel. Examples include insufficient knowledge of dementia, and limited attitudes, skills and competencies across all professional groups, which lead to poor care experiences and outcomes for people with dementia and their carers. UK policy is clear that dementia education needs to be improved (Department of Health (DH), 2009; 2013; 2015; Prince et al, 2016). People with dementia are frequent users of healthcare services. Consequently, there is a need for quality dementia education to ensure the future paramedic workforce is equipped with the skills to provide quality care to people living with dementia (DH, 2010; College of Paramedics (CoP), 2015)

\section{Importance of dementia education} A National Dementia Strategy, Living Well With Dementia (DH, 2009), highlighted deficiencies in both the knowledge and skills of health professionals caring for people with dementia. People living with dementia continue to experience care which can lack dignity, be frightening, and increase the complexity of both their physical and mental ill-health.

The DH and Skills for Care (2010) highlighted that as they set the standards for the future quality of NHS healthcare provision, a lack of education in the early stages of training may create a significant gap in paramedic knowledge of dementia. Therefore, it is essential that undergraduate education maximises the contribution of paramedic students to the delivery and quality of dementia care, as well as prepare them to make more person-focused decisions. 


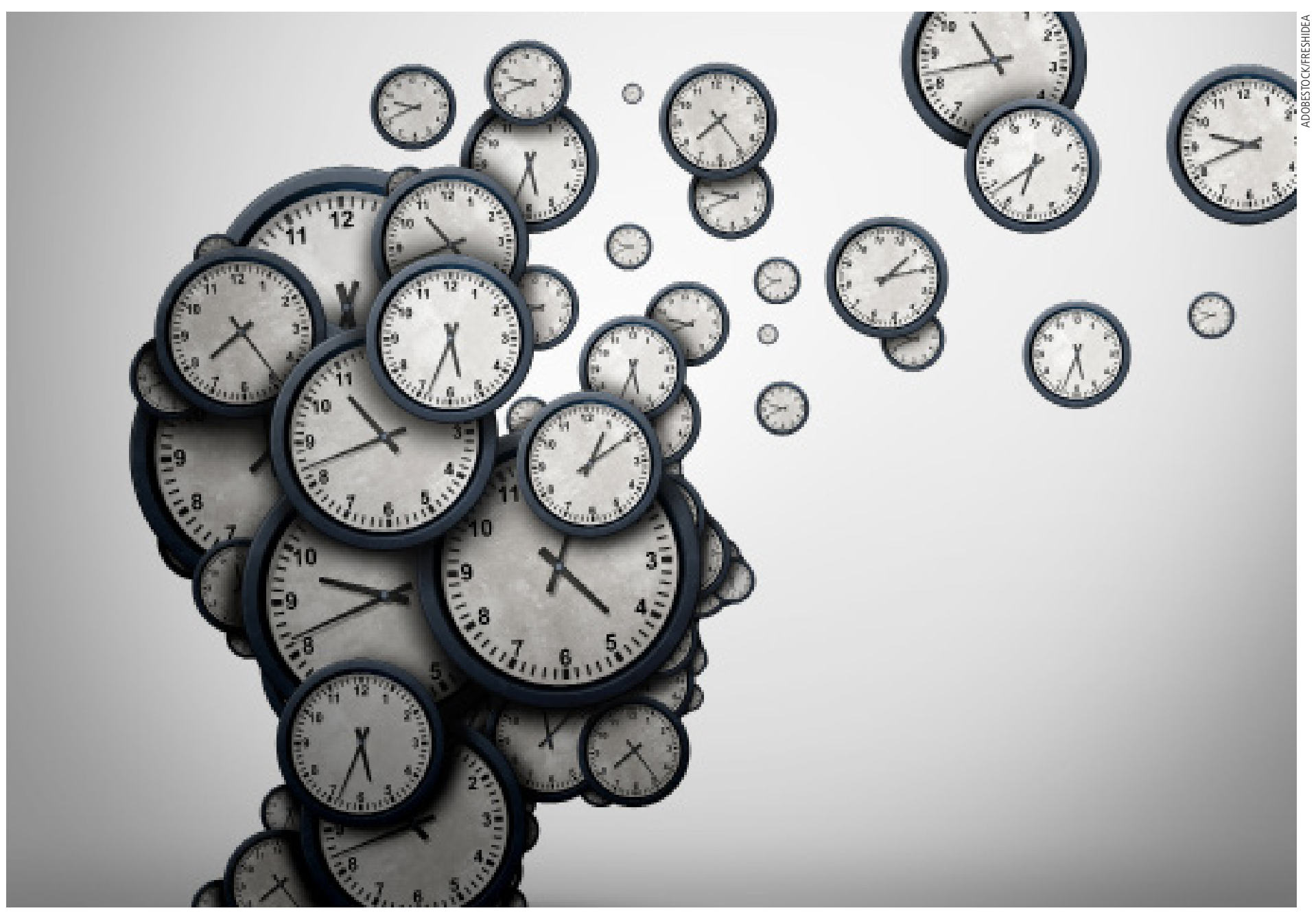

The Time for Dementia programme is aiming to foster more holistic empathetic and person-centred dementia care

\section{Background}

In response to the Prime Minister's challenge on dementia in 2010 and the Mandate from the Government 2015-2016 to Health Education England (HEE), all undergraduate healthcare courses have included dementia in their curriculum as of September 2015 (DH, 2013).

This should mean that all health and social care staff involved in the care of people with dementia have the necessary skills to provide the best quality care in all of their roles and settings. However, mandated dementia content in healthcare curricula presents Higher Education Institutions (HEIs) with challenges; for example, how best to integrate mandated dementia education into their curricula in a meaningful way, or the potential for there are also opportunities to prepare future health professionals to address the complexities of working with people with dementia.

If educators are to encourage paramedic students to learn about the whole person and not just the disease process, education needs to evolve in order to reflect this (Ironside et al, 2003). Critics argue that as a result of the curricula's focus on teaching technical skills, paramedic students are clinically competent but may lack the 'soft skills' needed to engage with a person with dementia, such as communication, empathy and compassion (Lazarsfeld-Jensen, 2010). The practice of health care is more than a completion of tasks-it involves good communication skills and the ability to manage care from the perspectives of the patient. Educational initiatives that involve service users may enable students to more fully understand the experiences of people with dementia, and foster patient-centred approaches to care.

In a quantitative psychology study, Mann and Himelein (2008) identified that the use of a firstperson narrative teaching approach reduced mental illness stigma in students when compared with a traditional diagnosis-centred approach. Engaging with the lived experiences of people with dementia offers paramedic students a different discourse to the professional one that is traditionally shared 


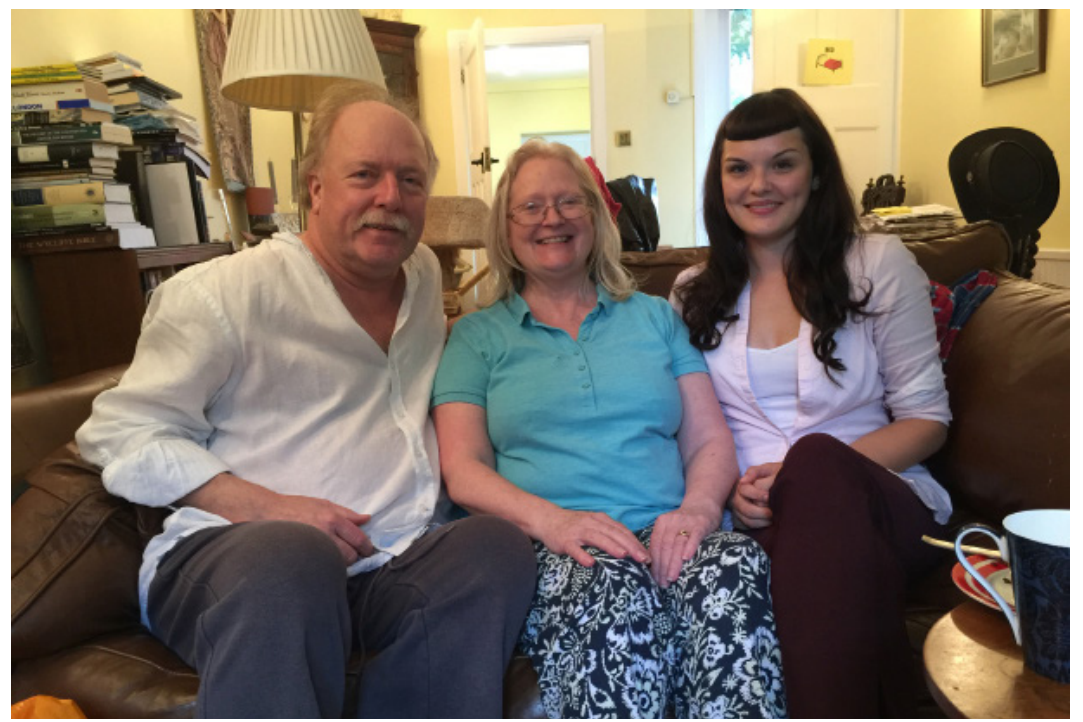

Time for Dementia snapshot: Pippa and Rob Stanley with University of Surrey 3rd year student, Charlotte Brennan

by academics. This enables them to see beyond the clinical aspects of their role as a paramedic, to include the essential human element of care.

In response to the DH's recognition of dementia as a national priority, the Association of Ambulance Chief Executives (2017) recently produced best practice guidance for ambulance services with regard to supporting people living with dementia. They propose best practice aims that reflect the ethos of the two key steps from the National Dementia Strategy (DH, 2009), which include:

- To deliver person-centred care that supports the person living with dementia

- To develop a skilled and effective workforce able to champion compassionate person-centred care. The Time for Dementia Programme aims to support these aims by promoting person-centred learning and encouraging paramedic students to see the person, rather than their dementia.

\section{Core curriculum for paramedics}

The Time for Dementia programme has been operational since November 2014. It is intended that these visits will provide a foundation for paramedic students to explore dementia through listening to the experiences and perspectives of people with dementia and their carers. Funded by HEE Kent, Surrey, Sussex, Time for Dementia is a 4-year collaborative project led by Professor Sube Banerjee at Brighton and Sussex Medical School and the School of Health Sciences, at the University of Surrey.

The programme aims to build on previous dementia healthcare educational programmes in the United States such as the Buddy Program and the Pairs Program. These use regular, recurrent placement visits to the same patients over a period of 12 months to provide continuity of contact, and opportunities to learn about dementia and patient experiences (Mohardt, 2006; Jefferson et al, 2012).

However, Time for Dementia differs from these previous initiatives in that it has been made a core part of the curriculum as opposed to a voluntary option (Banerjee et al, 2016). As far as the authors are aware, this is the first initiative of its kind to be incorporated into non-medical programmes and to provide a longitudinal experience of dementia.

The Time for Dementia programme visits run over 2 years and starts in the first year of study for paramedic students $(n=40)$ at the University of Surrey. The programme starts with an initial meeting where the programme is introduced, after which the students visit in pairs for 2 hours, approximately every 3 months. The visits are a core element of the curriculum and included within students' practice hours.

\section{Relevance to paramedic practice}

Paramedic programmes must respond to the changing needs of society. It is estimated that 850000 people live with dementia in the UK, and this figure is predicted to rise to 1 million by 2025 (Prince et al, 2014). According to Schubert et al (2006), people with dementia are on average dealing with $2-8$ multimorbidities. Most commonly, these include strokes, diabetes, falls, and frailty. Therefore, people living with dementia are more likely to be in need of ambulance services.

The Buswell et al (2016) analysis of call-outs over 4 days in two English counties revealed that $21.5 \%$ of call-outs were to people with dementia or cognitive impairment. Although educating paramedic students about dementia is essential to help prepare them for work in the field, studies have demonstrated a lack of education on caring for older adults and people with dementia in undergraduate paramedic programmes (Abbey et al, 2006; Annear et al, 2016).

It is essential that HEIs address this deficit because the role of paramedics has broadened to meet the non-emergency care needs of an ageing population (Mason et al, 2007a; 2007b), moving beyond the emergency transport role (DH, 2005; 2007; Ambulance Service Network, 2010; National Audit Office, 2011; NHS England, 2013).

Smith (2016) argues that traditional paramedic programmes have focused on clinical skills, leading to some paramedic students experiencing difficulty with social interactions across all aspects of training, and especially in dementia (Voss, 2016). The aim of Time for Dementia has been to provide paramedic students with opportunities to deepen their knowledge of dementia from the perspective of people living with the condition and their carers, 
so that they can work more effectively in practice. Visits are a unique opportunity for students to see the world of dementia through the eyes and stories of people with the condition.

This innovative and pioneering programme is being formally evaluated using a mixed-methods design led by the Centre for Dementia Studies, Brighton and Sussex Medical School (Banerjee et al, 2016). The findings of the programme are due by summer 2018. However, within the qualitative work, students and families (person with dementia, their family and carers) have highlighted the positive aspects of the programme so far.

\section{Reflective practice}

In particular, the visits have encouraged paramedic students to adopt the perspective of people with dementia, motivating them to reflect on their practice, and develop as paramedic practitioners. This is apparent in the following quotes from second-year paramedic students:

'I think having that personal view from someone in their environment as well, I think gives a small insight to it... That does help us deliver our care.'

'They always tell you the worst bits, and things like that, whereas there's a whole range of different things that dementia affects, not just the actual patient, and their day-to-day, but literally everything, from finance to relationships to family, I don't know, it's not that l'd ever not thought it affected that, I just never really thought about it before, I guess.'

'I reflected on how much that would affect me as a patient in the future, and sort of having that empathy, seeing through the patient's eyes, and it's not always the stuff that is overt, the stuff you're experiencing, you can't sort of express that. It's the experience, it's the exposure, it's the understanding of what they (the family) are going through, through their eyes, which is what this project has highlighted, which I wouldn't get on placement.'

\section{Conclusion}

The preliminary findings discussed in the current article indicate a promising effect on preparing undergraduate paramedic students for future practice. Brooke and Stiell (2017) highlight a lack of research involving paramedic education around the care of people with dementia and their families. Findings of this research could contribute to an undergraduate paramedic education framework that improves emergency dementia care. JPP

\section{Key Points}

- Visits to people with dementia provide paramedic students with a unique opportunity to develop their communication skills

- Findings may contribute to developing knowledge and practice, informing dementia curricula and dementia education for paramedic students

- Time for Dementia offers an alternative approach to traditional placements to allow students to develop an understanding of the human impact of dementia

- To keep education contemporary, curricula need to reflect the ageing population and evaluate how dementia education is mandated

\section{Conflict of Interest: None.}

\section{Acknowledgements: Health Education England Kent working across Kent, Surrey, Sussex funded the Time for Dementia Programme.}

\section{References}

Abbey J, Abbey B, Bridges P, Elder R, Lemeke P, Liddle J, Thornton R. Clinical placements in residential aged care facilities: the impact on nursing students' perceptions of aged care and the effect on career plans. Aus J Advan Nurs. 2006;23(4):14-19.

Alzheimer's Disease International. World Alzheimer Report 2010 The Global Economic Impact of Dementia [Internet]. Alzheimer's Disease International; 2010. [cited 2017 Sep 5]. Available from http://tinyurl.com/y9fnl4hm

Ambulance Service Network. Seeing ambulance services in a different light: more than a patient transport service. 2010; London: The NHS Confederation.

Annear M, Goldberg L, Lo A, Robinson A. Interprofessional curriculum development achieves results: initial evidence form a dementia-care protocol. J Interprofessional Care. 2016;30(3):391-393.

Association of Ambulance Chief Executives Dementia: Best Practice Guidance for Ambulance Services [Internet]. AACE; 2017. [cited 2017 Sep 1]. Available from http://tinyurl.com/ y9jewg8d

Banerjee S, Farina N, Daley S et al. How do we enhance undergraduate healthcare education in dementia? A review of the role of innovative approaches and development of the Time for Dementia Programme. Int J Geriatric Psychiatry. 2016;32:68-75.

Brooke J, Stiell M. Development of clinical and inter-personal skills to support people living with dementia. J Paramed Pract. 2017;8(8):348-353.

Buswell M, Lumbard P, Fleming J, Ayres D, Brayne C, Goodman C. Using ambulance service PCRs to understand 999 call-outs to older people with dementia. J Paramed Pract. 2016;8(5):246-251.

College of Paramedics. College of paramedics: Leading the development of the paramedic profession [Internet]. Paramedic Curriculum Guidance 3rd edn. Col Paramed; 2015. [cited 2017 Sep 7]. Available from http://tinyurl.com/hbwghec

Department of Health. Taking Healthcare to the Patient: Transforming NHS Ambulance Services. 2005; London: The Stationary Office. 
Department of Health. Urgent care pathways for older people with complex needs. 2007; London: The Stationary Office.

Department of Health. Living Well with Dementia: A National Dementia Strategy. London (UK): Department of Health; 2009.

Department of Health and Skills for Care. Working to support the implementation of the National Dementia Strategy project: Mapping existing accredited education/training and gap analysis report. 2010; London: DH.

Department of Health. Delivering high quality, effective, compassionate care: Developing the right people with the right skills and the right values. Government to Health Education England: April 2013 to March 2015. 2013; London: $\mathrm{DH}$.

Department of Health. Prime Minister Challenge on Dementia 2015-2020. London (UK): Department of Health; 2015.

Ironside P. New pedagogies for teaching thinking: The lived experiences of students and teachers enacting narrative pedagogy. J Nurs Edu. 2003;42(11):509-516.

Jefferson A, Canterwell N, Byerly L, Morhardt D. Medical student education program in Alzheimer's Disease: The PAIRS program. BMC Medical Education. 2012;12(80):1-8.

Mann C, Himelein M. Putting the person back into psychopathology: An intervention to reduce mental stigma in the classroom. Social Psychiatry and Psychiatric Epidemiology. 2008;43(7):545-551.

Mason S, O'Keefe C, Coleman P, Edlin R, Nicholl J. Effectiveness of emergency care practitioners working within existing emergency service models of care. Emerg Med J. 2007a;24(4):239-43

Mason S, Knowles E, Colwell B et al. Effectiveness of paramedic practitioners in attending 999 calls from elderly people in the community: cluster randomized control trial. BMJ. 2007b;335(7626):919-922.
Mohardt D. Educating medical students on Alzheimer's disease and related disorders: An overview of the Northwestern University Buddy Programme Dementia. Preventive Med. 2006;5(3):448-456.

Moon J, Fowler J. There is a story to be told: a framework for the conception for story in higher education and professional development. Nurse Edu Today. 2008;28(3):232-239.

National Audit Office. Transforming NHS Ambulance Services Report by the Comptroller and Auditor General [Internet]. NAO; 2011. [cited 2017 Sep 9]. Available from http://tinyurl. com/y8mgzyxe

NHS England. High quality care for all, now and for future generations; Transforming urgent and emergency care services in England [Internet]. The Evidence Base for the Urgent and Emergency Care Review. NHS England;2013. [cited 2017 Sep 9]. Available from http://tinyurl.com/nkbkqej

Prince M, Comas-Herrera A, Knapp M, Guerchet M, Karagiannidou M. World Alzheimer Report: Improving healthcare for people living with dementia. Coverage, quality and costs now and in the future. 2016;London: Alzheimer's Disease International.

Schubert C, Boustani M, Callaham C, Perkins AJ, Carney CP, Fox C, Unverzagt F, Hui S, Hendrie HC. Comorbidity profile of dementia patients in primary care: are they sicker? J Am Geriatr Soc. 2006;54(1):104-109

Smith G. Examination of undergraduate paramedic clinical placement within a traditional and novel setting. Australasian J Paramedicine. 2016;13(2):1-7.

Voss S, Black S, Brandling J et al. Home or hospital for people with dementia and one or more other multimorbidities. What is the potential to reduce avoidable emergency admission? The HOMEWARD Project Protocol [Internet]. BMJ Open. 2017;7(4):e016651. [cited 2017 Sep 9]. Available from http:// tinyurl.com/yczmoc $3 \mathrm{k}$

\section{CPD Reflection Questions}

- Why do you think it is important to promote person-centred care in dementia?

- What skills are important in the care of a person living with dementia?

- Reflect upon the role of the paramedic in dementia care. 